\title{
The Relationship Between Innovation Management, Social Innovation and Sustainable Performance in Mexican SMEs
}

\author{
Sandra Yesenia Pinzón-Castro ${ }^{1}$, Gonzalo Maldonado-Guzmán ${ }^{2}$ \\ and Rubén Michael Rodríguez-González ${ }^{3}$
}

\begin{abstract}
Social innovation is a relatively recent construct in the scientific literature in the field of marketing and has recently been considered an essential construct to achieve a higher level of sustainable performance in manufacturing companies, particularly in small and mediumsized companies. However, despite the importance of small and medium-sized enterprises in any country in the world, there are relatively few theoretical and empirical studies that have focused on the analysis and discussion of the relationship between social innovation and sustainable performance. in small and medium-sized companies, and there are even fewer studies that relate these two constructs to innovation management, especially in developing countries, such as Mexico. Therefore, the essential objective of this study is the analysis and discussion of the relationship between innovation management, social innovation and sustainable performance in small and medium-sized companies, for which a sample of 300 companies and the analysis of structural equations. The results obtained show the existence of a positive and significant relationship between innovation management and social innovation and sustainable performance, and between social innovation and sustainable performance.
\end{abstract}

Keywords: Innovation management, social innovation, Sustainable performance, SMEs.

JEL classification numbers: M21.

${ }^{1}$ Universidad Autónoma de Aguascalientes, Centro de Ciencias Económicas y Administrativas, Departamento de Mercadotecnia.

${ }^{2}$ Universidad Autónoma de Aguascalientes, Centro de Ciencias Económicas y Administrativas, Departamento de Mercadotecnia.

${ }^{3}$ Universidad Autónoma de Aguascalientes, Centro de Ciencias Económicas y Administrativas, Estudiante del Doctorado en Ciencias Administrativas.

Article Info: Received: November 10, 2021. Revised: December 10, 2021.

Published online: December 14, 2021. 


\section{Introduction}

Since the middle of the last century, innovation has become not only one of the most analyzed and discussed constructs in the scientific literature, but also in identifying the generation of knowledge derived from innovation activities and how to exploit that knowledge (Fagerberg et al., 2013), in a way that allows companies of all sizes and sectors to significantly improve their level of business performance (Geroski et al., 1993; Kraiczy, 2013; Hatak et al., 2016). Likewise, this concept has its origin in the study of economic development at the beginning of the last century, in such a way that Joseph Schumpeter in his book The Review of Economics Statistics (Analysis of Economic Change), considers that innovation is the engine of economic change (Schumpeter, 2003).

In recent times this concept has been widely strengthened, a clear example of this is that the Oslo Manual of the Organization for Economic Cooperation and Development considers that innovation can be defined as "the implementation of new or improved products (goods or services), processes (production and supply methods), marketing methods (packaging, sales, and distribution), or new management methods (best practices, workplace improvement, external relations, marketing)" (OECD, 2005: 46). Therefore, according to this definition, Innovation is not simply reduced to the generation of an idea, the invention of a new device, or the development of a new market, but it is a synergy of efforts through the integration of all the departments of a company (Guerra-Betancourt et al., 2005).

In this sense, recent publications have shown the importance of analyzing innovation as a social topic of interest to the scientific and business community, as proof of this are the recently published studies by Franz et al. (2012), Macaulay et al. (2012), Pitsis et al. (2013), Fagerberg et al. (2013) and Dodgson et al. (2014), who have characterized the multidisciplinary nature of the concept of innovation, which has traditionally been related to technological innovation (Teixeira et al., 2017). However, the scientific literature on this topic recognizes social elements as part of physical elements, since both are inherent in technological innovation in various ways (Tornatzky \& Fleischer, 1990), since innovation is a universal process of constant social change.

From this perspective, it is important to point out that the main objective of this study is the analysis and discussion of the relationship between innovation management, social innovation and sustainable performance of small and mediumsized enterprises (SMEs) in Mexico, and given that there are relatively few studies published in the literature that analyze and discuss the relationship between these three important constructs, the main contribution of this empirical study is the analysis and discussion of innovation management with social innovation and social innovation. business performance of SMEs in a country with an emerging economy, such as Mexico, as recommended by Salim et al. (2016) and Teixeira et al. (2017). 


\section{Preliminary Notes}

Innovation in the management activities of companies is generally related in the literature to essential changes in "the various rules and routines through which daily and work activities are carried out within organizations" (Birkinshaw et al., 2008: 828), in other words, in the firm management activities (Hamel, 2007). In addition, innovation in organizational structures requires changes and improvements in the distribution of functions, responsibilities, command lines and information flows (Armbruster et al., 2008), since innovation is commonly related to management processes such as strategic planning, budgeting, compensation, internal communication, and knowledge management (Hamel, 2007), but innovation management differs in process, product, marketing and strategy innovations (Teixeira et al., 2017).

Likewise, in the innovation literature it is commonly established that innovation management is carried out through two essential perspectives: diffusion and creation (Teixeira et al., 2017), since from these two perspectives innovation it means a totally new activity for the organization (Rogers, 2003), as well as the development of the initiation, adoption, and implementation stages of innovation activities (Damanpour, 2014). Similarly, the Oslo Manual suggests the stages of planning, development and implementation of new methods that are new to companies (OECD, 2005), for which it is possible to establish that the adoption of innovation management will depend fundamentally on the success of its dissemination, as well as of its adaptation and assimilation process, especially when it is related to the processes of social innovation and sustainable performance (Damanpour, 2014).

\subsection{Management of Innovation and Sustainable Performance}

The innovation management in companies can be analyzed, understood, and applied from three approaches: the first is one in which the innovation management is oriented in the internal organizational structure and its administration; the second reinforces the operational activities; and the third is the improvement of the culture and philosophy of the firm (Damanpour \& Aravind, 2011). Furthermore, the literature in the field of innovation establishes that innovation management is practically based on three fundamental principles: 1) innovation management must be market-oriented; 2) innovation management should be considered as a system; and 3) innovation management must have an objective and essential goals in companies (Arvanitis et al., 2016).

Likewise, in the literature two types of innovation management are also observed, the first of them refers to a type of gradual innovation, and the second is that of radical innovation, since in the management of gradual innovation, small innovations are made to improve business management, which allows innovation management to be more efficient, but this type of innovation involves a gradual process, frequently presents limitations, and has a short and visible life cycle. Regarding the management of radical innovation, generally in the literature it is 
established that it is carried out by professionals or entrepreneurs with experiences in innovation activities, when it is determined that the previous innovation management no longer works and it is necessary to carry out a new management (Palm, 2016).

Consequently, innovation management requires, for its better understanding, to be analyzed from a holistic point of view in which several factors converge, so that it can be effective and successful (Horn \& Brem, 2013). However, it is not exclusively the alignment of internal resources that causes success in innovation management. Rather, the innovation management process is an activity that is surrounded and influenced by internal and external factors (Cortimiglia et al., 2015). Hence, changes in these factors require changes in alignment and structure in the innovation management process. As stated by Sheu and Lee (2011), innovation management is not a static construct, but it can be adaptable to a series of activities that need to be optimized at any time.

Similarly, the use of innovation management is flexible and has, as Beletsky et al. (2008) has pointed out, a significantly positive influence on the performance of a new product or service. In this order of ideas, such enhancements are not limited to technological changes, and may be related to changes in processes, operational practices, and business models (Szekely \& Strebel, 2013). In addition, various researchers, academics, and industry professionals, such as Wagner (2010) and Gunday et al. (2011), have linked the effects of investments in innovation management with the sustainable performance of firms, asserting that the adoption of innovation management practices can significantly affect the sustainable performance of companies. However, business activities are responsible for many environmental and social problems, for which companies have an obligation to fulfill their social responsibility to improve the environment.

In this sense, the concern for sustainability is not of critical importance only for large companies, since according to Zee (2011) in an enhanced study with large and small firms in Germany, found that large companies are more likely to produce environmentally friendly products and services, while small firms are inclined to have higher levels of environmental awareness and a greater belief in the environment and sustainability theme. Therefore, the great challenge for SMEs is to innovate through the perspective of sustainable development, adding more value to products and processes, and minimizing the negative socio-environmental impacts that are the result of industrial activity, but are necessary. social changes to value these products and services (Charter \& Clark, 2007).

In the case of Mexican SMEs, it is common for them to have structures focused on ownership and control that allow them to reach and apply decisions more quickly (Lee, 2013). In addition, several of the SMEs reflect a large dose of self-sacrifice to ensure the continuity of the organization (Glover \& Reay, 2015), financing in most cases the investment plans with their own assets (Blanco-Mazagatos et al., 2007). Thus, in this way, Mexican companies demonstrate that they have the necessary requirements for the development of an adequate innovation management and its impact on the level of sustainable performance. 
Thus, considering the information presented, it is possible to propose the following research hypothesis:

\section{H1: A higher level of innovation management, higher level of sustainable performance.}

\subsection{Social innovation and sustainable performance}

Drucker (1986) was the first person to introduce the concept of social innovation during the modern management era, stating that management was the dominant power during the 1940s or 1950s in economies, but argued that the new dominant power for the next 20 or 30 years it would be the one that refers to the solution of social problems. Likewise, two decades later Drucker (2002) and Mulgan et al. (2006), concluded that the most important innovations should come from the social sectors, rather than from companies doing business, since it is in society where the adoption and implementation of innovation activities is most required.

In this sense, in the current literature the topic of social innovation is not limited and complex in its definition since numerous researchers around the world have had points of discrepancy and coincidence in its definition. For example, the Economic Commission for Latin America and the Caribbean defines social innovation as "new forms of management, administration and execution, new instruments or tools, new combinations of factors aimed at improving the social and living conditions in general of the population of the region" (ECLAC, 2015). However, the topic of social innovation is considered in the literature of the field of innovation as an emerging construct, which favors the debate on how the concept should be constructed and in what terms it should be used (Moulaert et al., 2005; Bignetti, 2011; Ferreira, 2012).

Likewise, social innovation addresses the various difficulties faced by society at a global level in issues such as social inequality, poverty, inequity, health, education, the environment, among others. All these problems that, because they are so similar and at the same time so different in their way of approaching and facing, do not imply that the solutions are the same for all nations; but through the approach between the various actors (government, private initiative, NGOs, academics, researchers, among others), an attempt is made to give answers to these difficulties, especially when it is related to the level of sustainable performance of the companies of all sizes and sectors.

In this order of ideas, social innovation arises because of the applied knowledge that society requires, through the participation and cooperation of the different actors involved in the innovation process, resulting in a new and perennial solution for groups. social, communities or society. According to Bignetti (2011), social innovation can be conceptualized as the means to achieve social change, seeking mechanisms to address different types of problems, among which are the improvement of the level of sustainable performance.

Analyzing the different definitions of social innovation provided by various 
researchers and academics, Cloutier (2003) concludes that, in general, social innovation is a "new response" to an unsatisfactory social scenario. In addition, Cloutier (2003) emphasizes that social innovation bears this title because it refers to the well-being of individuals and communities, which is specified as a lasting change, aimed at individual, territory, or company development, therefore, social innovation does not have a particular form, it can be seen as procedural, organizational or institutional. According to Neumeier (2012), social innovation has characteristics that, when compared with previous studies, have different forms of diffusion that go beyond temporary trends and with an effect on the future of sustainable development of society in general.

Additionally, social innovation has been analyzed as a new form of collaboration aimed at placing emphasis on the needs of society and/or achieving social change and has also had an increase in the promotion of public policy (Ayob et al., 2016), since the emphasis on public policy is a new way for the government to prioritize collaboration between the government and citizens. Notwithstanding, the everincreasing increase in the debates of politicians and society in general, social innovation continues to be a controversial concept, especially regarding the magnitude of said social change and its effects on the sustainable performance.

Under this context, there are two positions in the literature regarding social innovation and its effects on the level of sustainable performance. On the one hand, those researchers and academics who consider that social innovation is any result of innovation that responds mainly to the needs of society (Pol \& Ville, 2009). On the other hand, there are those researchers and academics who have a more radical position, considering that social innovation is an integrated process in sociocultural life and in the contexts of politics (Moulaert et al., 2005), which stimulates the collaboration of all sectors of the economy and tries to find the unjust power relations (Montgomery et al., 2012; Ayob et al., 2016; Ziegler, 2017). Thus, considering the information presented, it is possible to propose the following research hypothesis:

\section{H2: A higher level of social innovation, higher level of sustainable performance.}

\subsection{Innovation Management and Social Innovation}

Theories and approaches on innovation management and social innovation provide concepts that are similar and at the same time differ from each other. The similarities can be seen from the point of view that various social innovations require support for innovation management. However, if the impact on the results is considered, it goes beyond the initial purposes, therefore, social innovation turns out to be a broader concept. Social innovation not only considers management elements, but also factors related to innovation and results. In fact, it can be said that social innovation requires a certain level for innovation management. But not all innovation efforts, even when they impact on generating changes in social relations, have the attributes of social innovation (Teixeira et al., 2017). 
When the concepts through which such innovations originate are considered, creation and diffusion are very inflexible. In relation to creation, innovation management involves internal and external personnel, this is commonly done in different stages such as motivation, invention, application and labeling of the theory (Birkinshaw et al., 2008). Instead, to carry out dissemination, it goes hand in hand in decision making, considering, planning, adaptation, and implementation. Like the previous one, it also involves internal and external personnel, but with different roles than those mentioned in the creation. Instead, the concept of social innovation ranges from creating and developing to maintaining and expanding to achieve systemic change. This concept is local and territorial, in the same way with the participation of internal and external personnel (Mulgan, 2006, 2010; Oliveira \& Breda-Vázquez, 2012; Buckland \& Murillo, 2014).

Although it is true that, both in the innovation management and social innovation, personnel internal or external to the company intervene, these may occupy hybrid functions at different times, for example, as a consultant or as a manager. In the latter case, the need to partner is fundamental, since joint actions are required with non-profit organizations, civil organizations, families, and leaders, being key to achieve truly systemic changes (Pol \& Ville, 2009; Mulgan, 2010; Klein, 2013).

As can be seen, either in their results or in their consequences, both types of innovations are extremely complex, and efforts to innovate may be unsuccessful in both cases. Innovation management may imply a performance result that is difficult to measure, such as the impact on employees and other actors (Volberda et al., 2013). Similarly, the results of social innovation depend on its level of institutional commitment and can be perceived in new forms of organization and social relationships, new or improved products, services, laws, regulations, procedures, models, strategies, and institutional programs. The results of social innovation also include advances in well-being, sustainability, social and political inclusion, as well as quality of life, particularly for the most vulnerable and marginalized groups (André \& Abreu, 2006; Pol \& Ville, 2009; Mulgan, 2010; Hart et al., 2015).

In this sense, the methodological diversity highlights the different levels of analysis and abstraction that are required and used for research in innovation management and social innovation, it is also highlighted that these constructs have carried out exhaustive investigations in cases of study, as well as longitudinal investigations, detailing the processes of generation, adoption and diffusion (Volberda et al., 2013; Pitsis et al., 2013). However, the scientific community is interested in large-scale comparative international surveys based on standardized measures, such as those of the Oslo Manual (OECD, 2005), although Damanpour (2014) mentions that it has some restrictions. Finally, in the case of social innovation, researchers focus on its scope of development, including the factors that facilitate application, and placing emphasis on successful experiences (Parente et al., 2014). Therefore, considering the information presented, it is possible to propose the following research hypothesis: 
H3: A higher level of innovation management, higher the level of social innovation.

On the other hand, to respond to the three research hypotheses raised in this work, an empirical study was carried out in the manufacturing companies of the state of Aguascalientes (Mexico), using the business directory available in the Business Information System of Mexico (SIEM) for the State of Aguascalientes in 2019, which had a record as of May of 1,350 manufacturing companies with 5 to 250 workers. In addition, a survey was designed that was applied to the managers of the companies, and it was applied to a sample of 300 companies selected through a simple random sampling with an error of $\pm 5 \%$ and a significance level of $95 \%$, representing said sample a little more than $22 \%$ of the total population under study, and the survey was applied during the months of May to July 2019.

Likewise, for the measurement of innovation management, an adaptation was made to the scale proposed by Kunz and Linder (2015), who considered that innovation management can be measured through 9 items. About social innovation, this was measured through an adaptation to the scale proposed by Pot and Vaas (2008), who considered that it can be measured through 12 items. Finally, for the measurement of sustainable performance, an adaptation was made to the scale proposed by Gadenne et al. (2012), who considered that this can be measured through 5 items. All the items on the three scales were measured using a 5-point Likert-type scale with $1=$ completely disagree to $5=$ completely agree as limits.

In addition, for the evaluation of the reliability and validity of the three scales used in this study, a Confirmatory Factor Analysis (CFA) was applied, using the maximum likelihood method with the SmartPLS 3.3 software (Hair et al., 2019). Thus, reliability and validity were measured with Cronbach's Alpha and the Composite Reliability Index (CRI), and the Extracted Variance Index (EVI), respectively (Bagozzi \& Yi, 1988), to assess the consistency internal of the three scales (Hair et al., 2019). The results obtained indicate that the Cronbach's Alpha and CRI values are higher than 0.7 , as well as the EVI are higher than 0.5 , which indicates the existence of reliability of the innovation management, social innovation, and sustainable performance scales (Nunally \& Bernstein, 1994, Hair et al., 2017). Table 1 shows the results obtained in greater detail.

Table 1: Convergent, Reliability and Validity

\begin{tabular}{|l|c|c|c|}
\hline \multicolumn{1}{|c|}{ Variable } & Cronbach Alpha & CRI & EVI \\
\hline Innovation Management & 0.960 & 0.958 & 0.718 \\
\hline Social Innovation & 0.948 & 0.951 & 0.619 \\
\hline Sustainable Performance & 0.865 & 0.863 & 0.561 \\
\hline
\end{tabular}


In addition, the assessment of the scales also includes the discriminant validity, which is measured through three elements: the Fornell and Larcker criterion, the cross loads and the heterotrait-monotrair ratio (HTMT) of correlations (Hair et al., 2019). Given that a structural equation model will be used through the Partial Least Squares (PLS-SEM), it was considered convenient for this empirical study to use the HTMT to measure the discriminant validity of the three measurement scales. Therefore, discriminant validity indicates the degree to which a construct is truly different from the other constructs (Hair et al., 2019). The most effective measure for its measurement is the HTMT (Henseler et al., 2015), since technically it is an estimate of what the real correlation between the three constructs would be if they were measured in a perfect way, for which a HTMT value less than 0.85 (Henseler et al., 2015).

Table 2: Discriminant Validity (HTMT)

\begin{tabular}{|l|c|c|c|}
\hline \multicolumn{1}{|c|}{ Variables } & $\begin{array}{c}\text { Innovation } \\
\text { Management }\end{array}$ & $\begin{array}{c}\text { Social } \\
\text { Innovation }\end{array}$ & $\begin{array}{c}\text { Sustainable } \\
\text { Performance }\end{array}$ \\
\hline Innovation Management & & & \\
\hline Social Innovation & 0.377 & & \\
\hline Sustainable Performance & 0.371 & 0.474 & \\
\hline
\end{tabular}

Table 2 shows the HTMT values of the three related constructs (innovation management, social innovation and sustainable performance), and it can be seen that the value of the three relationships is $0.377,0.371$ and 0.474 is clearly below the threshold plus conservative of 0.85 as a relevant minimum level. Therefore, it is possible to establish, according to the results obtained, that the scales that measure the relationship between innovation management, social innovation and sustainable performance have a discriminant validity, that is, the three constructs are measuring different things, but they are related to each other (Hair et al., 2019).

\section{Main Results}

To respond to the three hypotheses raised in this study, a structural equation model was applied with the support of the SmartPLS 3.3 software (Hair et al., 2019), analyzing the nomological validity of the theoretical model of innovation management, social innovation and sustainable performance through the Chi-square test, by means of which the results obtained between the theoretical model and the measurement model were compared, obtaining non-significant results which allows establishing an explanation of the relationships observed between the constructs latent (Anderson \& Gerbing, 1988; Hatcher, 1994). The results obtained are shown in the nomogram presented in the following figure. 


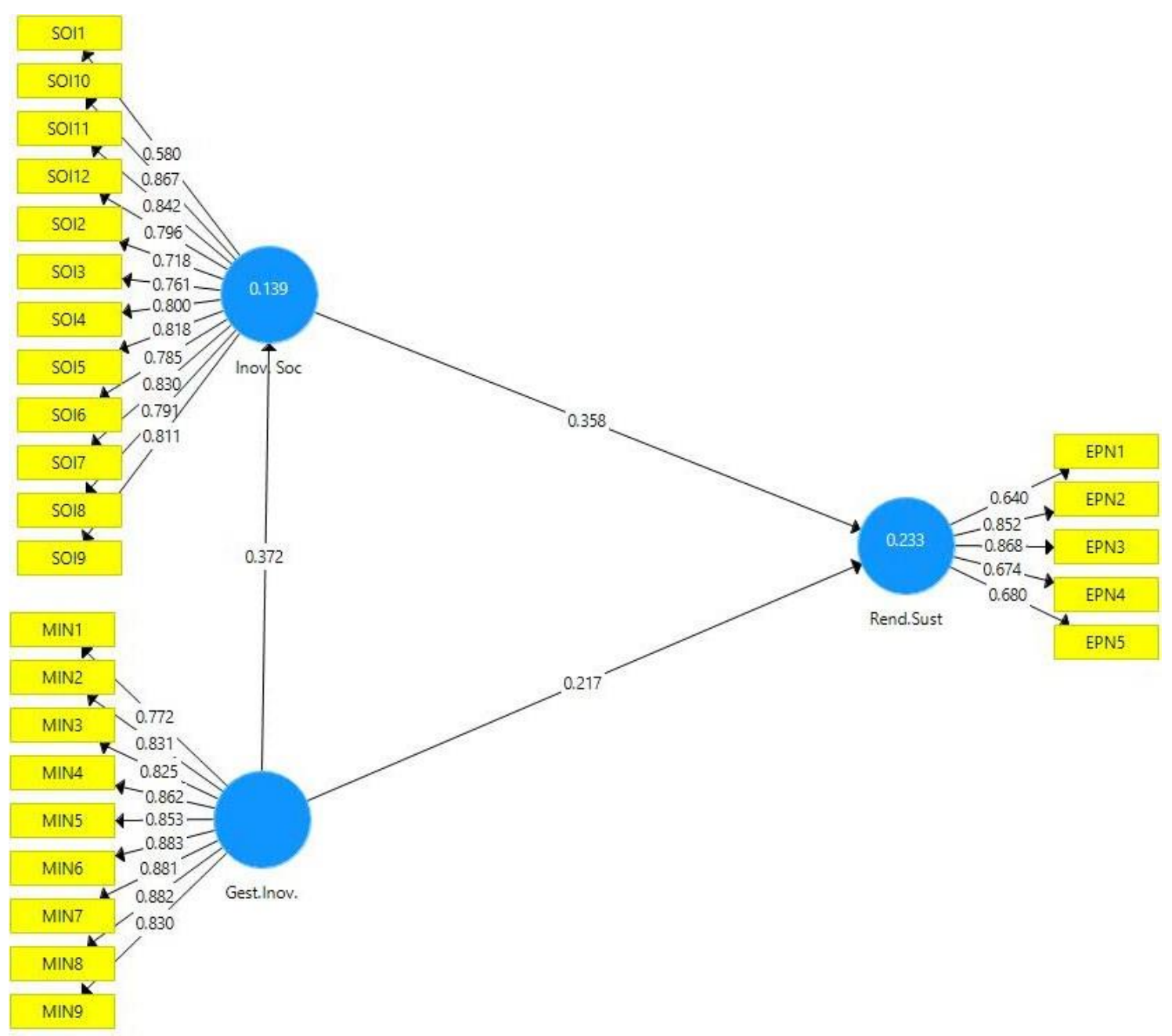

Figure 1: Nomogram of the PLS-SEM application

Figure 1 shows the values of the standardized factor loadings of innovation management, social innovation, and sustainable performance, and they are mostly higher than 0.70, which indicates the existence of internal reliability (Hair et al., 2019). Additionally, the value of the standardized coefficients $(0.372 ; 0.217 ; 0.358$; $\mathrm{p}<0.01)$ can also be appreciated, which establishes that innovation management has significant positive effects on social innovation and sustainable performance, as well as social innovation has significant positive effects on sustainable performance in SMEs in Mexico. However, to be certain that the data on the relationship between these three constructs are significant, it is necessary to review the data from the HTMT confidence interval by applying bootstrapping (Dijkstra \& Henseler, 2015). 
Table 3: Bootstrapping Confidence Intervals

\begin{tabular}{|l|c|c|c|c|c|}
\hline \multicolumn{1}{|c|}{ Variables } & $\begin{array}{c}\text { Original } \\
\text { Sample (O) }\end{array}$ & $\begin{array}{c}\text { Sample } \\
\text { Mean (M) }\end{array}$ & Bias & $\mathbf{2 . 5 \%}$ & $\mathbf{9 7 . 5 \%}$ \\
\hline Innovation Management $\rightarrow$ Social Innovation & 0.377 & 0.378 & 0.000 & 0.261 & 0.492 \\
\hline $\begin{array}{l}\text { Innovation Management } \rightarrow \text { Sustainable } \\
\text { Performance }\end{array}$ & 0.371 & 0.372 & 0.002 & 0.255 & 0.494 \\
\hline Social Innovation $\rightarrow$ Sustainable Performance & 0.474 & 0.474 & 0.000 & 0.344 & 0.592 \\
\hline
\end{tabular}

Table 3 shows the values obtained from the confidence interval of the HTMT at $2.5 \%$ and $97.5 \%$ in the bootstrapping analysis, and it can be observed that both in the lower and upper intervals there is no value of 1 , which indicates the existence of the stability of the estimation of the coefficients of the relationships between innovation management, social innovation and sustainable performance (Dijkstra \& Henseler, 2015). These results suggest that the directors of Mexican SMEs should focus their efforts on significantly increasing the activities of both innovation management and social innovation, as this will facilitate the achievement of a higher level of sustainable performance.

Additionally, these results have various implications for both managers and SMEs in Mexico, the first of which is related to obtaining the data derived from the application of the 300 surveys, which allowed a robust analysis to be carried out of the existing relationship between innovation management, social innovation, and sustainable performance in one of the most important sectors for the Mexican economy and society (SMEs), for which in future studies it would be essential to analyze these same three constructs in case studies of success, or in longitudinal studies. Therefore, it is not surprising that in the innovation literature researchers, academics and industry professionals consider that innovation management and social innovation play an essential role in obtaining a higher level of sustainable performance.

A second implication derived from the results obtained is that innovation management activities have a greater positive influence on social innovation than on the level of sustainable performance, like what had already been established in previously published studies (Mulgan, 2010; Hart et al., 2015; Teixeira et al., 2017). Therefore, innovation management represents a substantial activity in companies, particularly in manufacturing SMEs, since generally when innovation management activities are increased and improved, it is more likely that innovation activities will also do so. social innovation, which will facilitate not only obtaining better results, but also increasing sustainable performance.

A third implication emanating from the results obtained is that most of the studies published in the literature in the field of innovation have practically been oriented towards the analysis and discussion of the relationship between innovation management, social innovation, and performance. sustainable in developed countries, leaving aside its analysis in developing countries and emerging economies, such as Mexico. Therefore, it is important to establish that SMEs 
represent most of the companies established in these types of countries, in addition to being the essential source of economic and social development, for which it is essential that researchers, academics and professionals of the industry focus their studies on the analysis and discussion of these three constructs to provide robust empirical evidence.

A fourth and final implication derived from the results obtained is that the adoption of the different activities of innovation management, as well as of social innovation, require various changes in SMEs, which is why it is essential that the managers of companies involve their main business partners in the implementation of innovation management activities, as this will facilitate not only the development of social innovation activities, but also the achievement of a substantial increase in the level of sustainable performance. Therefore, it is not surprising that, in the current literature in the field of innovation, innovation management is considered an essential business strategy that is being implemented more and more in a greater number of SMEs.

\section{Conclusion}

The results obtained in this study allow different conclusions to be drawn, among which the following should be mentioned. A first conclusion derived from the results obtained is that the estimated theoretical model has high internal consistency, since the results obtained allowed a high correlation between innovation management, social innovation and sustainable performance. which allowed the three hypotheses raised in the study to be accepted. A second conclusion is that, additionally, the same estimated model allowed a general vision of the main activities of innovation management, as well as of social innovation, which facilitated both the generation of knowledge and empirical evidence on the importance they have. these three constructs in SMEs.

A third conclusion derived from the results obtained is that the studies that have been published in the literature in the field of innovation, which analyze and discuss the relationship between the activities of innovation management, social innovation and sustainable performance are relatively scarce compared to studies that have focused on the conceptualization of these constructs (Teixeira et al., 2017), which from our point of view lack a substantial contribution to the generation of knowledge, as they do not provide empirical evidence that allows establishing the effects of innovation management on social innovation and sustainable performance of SMEs, which does not allow corroborating the results obtained in this study with studies previously published in the literature.

A fourth conclusion from the results obtained is that the relationship between the activities of innovation management, social innovation, and the level of sustainable performance in SMEs is a relatively recent topic in the literature in the field of innovation. However, even when this topic is attracting the attention of the scientific, academic, and business community, it is possible to conclude in general terms that this topic is unfinished and open to discussion (Teixeira et al., 2017). A fifth and 
conclusion emanating from the results obtained is that the analysis and discussion of the relationship between innovation management, social innovation, and the level of sustainable performance in SMEs in emerging economy countries, as is the case of Mexico has not been explored in the current scientific literature in the field of innovation, therefore this study provides empirical evidence and new knowledge of the relationship between these three constructs.

\section{References}

[1] Anderson, J. and Gerbing, B. (1988). Structural equation modeling in practice: A review and recommended two-step approach. Psychological Bulletin, 13(1), (1988), 411-423.

[2] André, I. and Abreu, A. (2006). Dimensões e espaços da inovação social. Finisterra, 51(81), (2006), 121-141.

[3] Armbruster, H., Bikfalvi, A., Kinkel, S., and Lay, G. (2008). Organizational innovation: the challenge of measuring non-technical innovation in large-scale surveys. Technovation, 28(10), (2008), 644-657.

[4] Arvanitis , R., Villavicencio, D., and Wei, Z. (2016). L'apprentissage technologique dans les pays émergents. France: Société d'Anthropologie des Connaissances. 2016.

[5] Ayob, N., Teasdale, S., and Fagan, K. (2016). How Social Innovation 'Came to Be': Tracing the Evolution of a Contested Concept. London: Cambridge University Press. 2016.

[6] Bagozzi, R., and Yi, Y. (1988). On the evaluation of structural equation models. ournal of the Academy of Marketing Science, 16(1), (1988), 74-94.

[7] Beletsky, V., Davis, C., Anderson, E., and Burris, S. (2008). The law (and politics) of safe injection facilities in the United States. American. American Journal of Public Health, 98(2), (2008), 237-247.

[8] Bignetti, L. (2011). As inovações sociais: uma incursão por ideias, tendências e focos de pesquisa. Ciências Sociais Unisinos, 47(1), (2011), 3-14.

[9] Birkinshaw, J., Hamel, G., and Mol, M. (2008). Management innovation. Academy of Management Review, 12(7), (2008), 825-845.

[10] Blanco-Mazagatos , V., Quevedo-Puente, E., and Castrillo, L. (2007). The trade-off between financial resources and agency costs in the family business: an exploratory study. Family Business Review, 20(3), (2007), 199-213.

[11] Buckland, H., and Murillo, D. (2014). La Innovación Social en América Latina: Marco conceptual y agentes. Barcelona: Instituto de Innovación Social/Fondo Multilateral de Inversiones. 2014.

[12] Charter, M., and Clark, T. (2007). Sustainable innovation: Key conclusions from sustainable innovation conferences 2003-2006 organised by the centre for sustainable design. London: The Centre for Sustainable Design. 2007.

[13] Cloutier, J. (2003). Qu'est-ce que l'innovation sociale? Quebec: Centre de Recherche sur lês Innovations Sociales. 2003. 
[14] Cortimiglia , M., Maxime Delcourt, C., Thome de Olveira, D., Hans Correa, C., and Ferreira Danilevicz, A. (2015). A systematic literature review on firmlevel innovation management. International Association for Management of Technology, 17(2), (2015), 65-76.

[15] Damanpour, F. (2014). Footnotes to research on management innovation. Organization Studies, 35(9), (2014), 1265-1285.

[16] Damanpour, F., and Aravind, D. (2011). Managerial innovation: conceptions, processes, and antecedents. Management and Organization Review, 8(2), (2011), 423-454.

[17] Dijkstra, T., and Henseler, J. (2015). Consistent partial least squares path modeling. MIS Quarterly, 39(2), (2015), 297-316.

[18] Dodgson, M., Gann, D., and Phillips, N. (2014). The Oxford Handbook of Innovation Management. Oxford: Oxford University Press. 2014.

[19] Drucker, P. (1986). Innovation and entrepreneurship. New York: Harper Business. 1986.

[20] Drucker, P. (2002). Managing in the next society. New York: Truman Talley Books. 2002.

[21] ECLAC (Economic Commision for Latin American and the Caribbean). Panorama Temático Laboral: Transición a la Formalidad en América Latina y el Caribe, Lima: ILO Regional Office for Latin America and the Caribbean. 2015.

[22] Fagerberg, J., Martin , B., and Andersen, E. (2013). Innovation Studies: Evolution and Future Challenges. Oxford University Press, Oxford. 2013.

[23] Ferreira, J. (2012). Dimensões de Inovações Organizacionaise Sociais No Processode Certificação Fair Trade: oCaso daCasaAPIS, Dissertação deMestrado. Fortaleza, Ceará: Universidade Federal do Ceará. 2012.

[24] Franz, H., Hochgerner, J., and Howaldt, J. (2012). Challenge social innovation: an introduction. Challenge Social Innovation, 8(1), (2012), 1-16.

[25] Gadenne, D., Mia, L., Sands, J., Winata, L., and Hooi, G. (2012). The influence of sustainability performance management practices on organizational sustainability performance. Journal of Accounting \& Organizational Change, 8(2), (2012), 210-235.

[26] Geroski, P., Machin, S., and Van Reenen, J. (1993). The profitability of innovating firms. The RAND Journal of Economics, 24(2), (1993), 198-211.

[27] Glover, J., and Reay, T. (2015). Sustaining the family business with minimal financial rewards. How do family farms continue. Family Business Review, 28(2), (2015), 163-177.

[28] Guerra-Betancourt, K., Pérez-Campdesuñer, R., and Fornet-Hernández, E. (2005). Propuesta de una tecnología para la gestión de proyectos de innovación en el sistema territorial de ciencia e innovación en Cuba. Revista Cubana de Información en Ciencias de la Salud, 8(2), (2005), 367-381.

[29] Gunday, G., Ulusoy, g., Kilic, K., and Alpkan, L. (2011). Modeling innovation: determinants of innovativeness and the impact of innovation on firm performance. IEEE, 7(2), (2011), 87-95. 
[30] Hair, J., Black, W., Babin , B., and Anderson , R. (2017). Multivariate Data Analysis. Harlow: Pearson Education. 2017.

[31] Hair, J., Hult, T., Ringle, C., Sarstedt, M., Castillo, J., Cepeda, G., and Roldan, J. (2019). Manual de Partial Least Squares PLS-SEM. Madrid: OmniaScience. 2019.

[32] Hamel, G. (2007). The Future of Management. Boston, MA: Harvard Business School Publishing. 2007.

[33] Hart, T., Ramoroka, K., Jacob, P., and Letty, B. (2015). Revealing the social face of innovation. South African Journal of Science, 111(9/10), (2015), 1-16.

[34] Hatak , I., Kautonen, T., Fink , M., and Kansikas, J. (2016). Innovativeness and family-firm performance: the moderating effect of family commitment. Technological Forecasting and Social Change, 102(1), (2016), 120-131.

[35] Hatcher, L. (1994). A Step by Step Approach to Using the SAS System for Factor Analysis and Structural Equation Modeling. Cary, NC: SAS Institute Inc. 1994.

[36] Henseler, J., Rngle, C., and Sarstedt, M. (2015). A new criterion for assessing discriminant validity in variance-based structural equation modeling. Journal of the Academy of Marketing Science, 43(1), (2015), 115-135.

[37] Horn, C., and Brem, A. (2013). Stratigic directions on innovation management: A conceptual framework. Management Research Review, 36(10), (2013), 939954.

[38] Klein, J. L. (2013). Introduction: social innovation at the crossroads between science, economy and society. International Handbook on Social Innovation, 7(1), (2013), 9-16.

[39] Kraiczy, N. (2013). Innovations in Small and Medium-Sized Family Firms. An Analysis of Innovation-Related Top Management Team Behaviors and Family Firm Specific Characteristics. Wiesbaden: Springer Gabler. 2013.

[40] Kunz, J., and Linder, S. (2015). With a view to make things better: Individual characteristics and intentions to engage in management innovation. Journal of Management Governance, 19(1), (2015), 525-556.

[41] Lee, K. (2013). Schumpeterian Analysis of Economic Catch-Up: Knowledge, Path-Creation, and the Middle-Income Trap. New York, NY: Cambridge University Press. 2013.

[42] Macaulay, L., Miles, I., Wilby, J., Tan, Y., Zhao , L., and Theodoulidis, B. (2012). Case Studies in Service Innovation. New York: Springer. 2012.

[43] Montgomery, A., Dacin, P., and Dacin, M. (2012). Collective social entrepreneurship: Collaboratively shaping social good. Journal. Journal of Business Ethics, 111(3), (2012), 375-388.

[44] Moulaert, F., Martinelli, F., Swyngedouw, E., and Gonzalez, S. (2005). Towards alternative model(s) of local innovation. Urban Studies, 42(11), (2005), 1969-1990.

[45] Mulgan, G. (2010). Inovação social. In Azevedo, C., Franco, R.C. and Menezes, J.W. (Eds), Gestão de Organizações Sem Fins Lucrativos: o desafio da inovação social. Porto: Uniarte Gráfica. 2010. 
[46] Mulgan, G., (2006). Wilkie, N., Tucker, S., Ali, R., David, F., and Liptrot, T. Social silicon valleys: a manifesto for social innovation: what it is, why it matters, and how it can be accelerated. New York: Young Foundation. 2006.

[47] Neumeier, S. (2012). Why do social innovations in rural development matter and should they be considered more seriously in rural development research?proposal for a stronger focus on social innovations in rural development. Sociology Rural, 52(1), (2012), 48-69.

[48] Nunally, J., and Bernstein, C. (1994). Psychometric Theory. New York: McGraw-Hill. 1994.

[49] OECD. Manual de Oslo, Organização para Cooperação e Desenvolvimento Econômico. Paris: OECD. 2005.

[50] Oliveira, C., and Breda-Vázquez, I. (2012). Creativity and social innovation: what can urban policies learn from sectoral experiences? International Journal ofUrban and Regional Research, 36(3), (2012), 522-538.

[51] Palm, A. (2016). Local factors driving the diffusion of solar photovoltaics in Sweden: A case study of five municipalities in an early market. Energy Research \& Social Science, 8(1), (2016), 1-12.

[52] Parente, C., Marcos, N., and Diogo, V. (2014). Sobre inovação e empreendedorismo socia. Porto: Universidade do Porto. 2014.

[53] Pitsis, T., Simpson, A., and Dehlin, E. (2013). Handbook of Organizational and Managerial Innovation. Cheltenham: Edward Elgar. 2013.

[54] Pol, E., and Ville, S. (2009). Social innovation: buzz word or enduring term? The Journal of Socio-Economics, 38(6), (2009), 878-885.

[55] Pot, F., and Vaas, F. (2008). Social innovation, the new challenge for Europe. International Journal of Productivity and Performance Management, 57(6), (2008), 468-473.

[56] Rogers, E. (2003). Diffusion of Innovations. New York: Free Press. 2003.

[57] Salim, B., Ibrahim, S., and Ellingstan, P. (2016). Social innovation model for business performance and innovation. International Journal of Productivity and Performance Management, 65(2), (2016), 11-19.

[58] Schumpeter, J. (2003). Teoria do Desenvolvimento Econômico. Sao Paulo: Nova Cultural. 2003.

[59] Sheu, J.B., and Lee, W. (2011). Green Supply Chain Management: Trends, Challenges, and Solutions. Transportation Research Part E: Logistics and Transportation Review, 8(6), (2011), 791-792.

[60] Szekely, F., and Strebel, H. (2013). Incremental, radical and game-changing: strategic innovation for sustainability. London: Emerald Group Publishing Limited. 2013.

[61] Teixeira, D., Dos Santos Vieiria, N., Queiroz Barbosa, A., and Parente, C. (2017). Management innovation and social innovation: convergences and divergences. Academia Revista Latinoamericana de Administracion, 9(3), (2017), 474-489.

[62] Tornatzky, L., and Fleischer, M. (1990). The Processes ofTechnological Innovation. Lexington: Lexington Books. 1990. 
[63] Volberda, H., Van Den Bosch, F., and Heiji, C. (2013). Management innovation: management as fertile ground for innovation. European Management Review, 10(1), (2013), 1-15.

[64] Wagner, W. (2010). It Isn't Easy Being a Bureaucratic Expert: Celebrating the EPA's Innovations. Brusels: The Environmental Protection Agency. 2010.

[65] Zee, U. (2011). Why Australia and Indian researchers should collaborate to advance wound management innovation? Journal of Cutaneous and Aesthetic Surgery, 5(2), (2011), 120-131.

[66] Ziegler, R. (2017). Social innovation as a collaborative concept. Innovation: The European Journal of Social Sciences, 30(4), (2017), 388-405. 